\title{
Investigation of ATM, TP53 and MDM2 polymorphisms and their association with outcome of radiotherapy for prostate cancer
}

\author{
Hellen S Cintra ${ }^{1,2^{*}}$, Juliana CD Pinezi ${ }^{2}$, Ana Terra S Carvalho ${ }^{1,2}$, Thalles ED Santos ${ }^{1}$, Ricardo D Marciano ${ }^{1}$, \\ Renata BA Soares ${ }^{1,2}$
}

From São Paulo Advanced School of Comparative Oncology

Águas de São Pedro, Brazil. 30 September - 6 October 2012

\section{Background}

The purpose of this study was to evaluate the association of polymorphisms of ATM and TP53 genes in prostate cancer patients with morbidity after radiotherapy. These two genes encode important proteins of the DNA repair pathways. It is believed that their polymorphisms are likely to modify the response of normal tissues to radiation.

\section{Patients and methods}

After signing the informed consent agreement, a sample of peripheral blood of 50 patients from Araújo Jorge Hospital was collected to verify the presence of a ATM (rs1801516), TP53 (rs1042522, rs1800371, rs17878362, rs17883323 and rs35117667) and MDM2 (rs2279744) polymorphisms. The side effects were classified according to the Radiation Therapy Oncology Group (RTOG) score.

\section{Results}

On univariate analysis, hypertension was strongly associated with a decreased risk of late urinary toxicities $(\mathrm{OR}=$ $0,048,95 \%$ CI $0,004-0,620 ; p=0,022$ ). Patients receiving hormone therapy had a significantly higher incidence of acute skin toxicity $(\mathrm{OR}=27,66795 \% C I: 1,203-636,11 ; p=$ 0,029 ). The exchange $C>T$ in the position 11322 (intron 3 ) of the TP53 gene (rs35117667) was significantly associated with the risk of acute skin toxicity (OR=0,012 95\% CI $0,0004-0,317 ; p=0,006)$. No significant associations were found for the remaining polymorphisms $(\mathrm{p}>0,05)$.

\section{Conclusion(s)}

We conclude that hypertension seems to be protective for late urinary effects of radiotherapy. Hormonal therapy and the intronic TP53 polymorphism, rs35117667, were associated to increased acute skin radiosensitivity. This observation corroborates the importance of investigating the genetic profile to predict adverse side effects in patients undergoing radiotherapy.

\section{Financial support}

FINEP, FAPEG and CAPES.

\section{Author details}

${ }^{1}$ Genetic Masters Program, PROPE, Pontifícia Universidade Católica de Goiás, Goiânia, GO, Brazil. ²Radiobiology and Oncogenetic Laboratory, Research Education Institute - Associação de Combate ao Câncer em Goiás (ACCG), Goiânia, GO, Brazil

Published: 4 April 2013

\section{doi:10.1186/1753-6561-7-S2-P29}

Cite this article as: Cintra et al.: Investigation of ATM, TP53 and MDM2 polymorphisms and their association with outcome of radiotherapy for prostate cancer. BMC Proceedings 2013 7(Suppl 2):P29.

\footnotetext{
* Correspondence: hellencintra@hotmail.com

'Genetic Masters Program, PROPE, Pontifícia Universidade Católica de Goiás, Goiânia, GO, Brazil

Full list of author information is available at the end of the article
} 